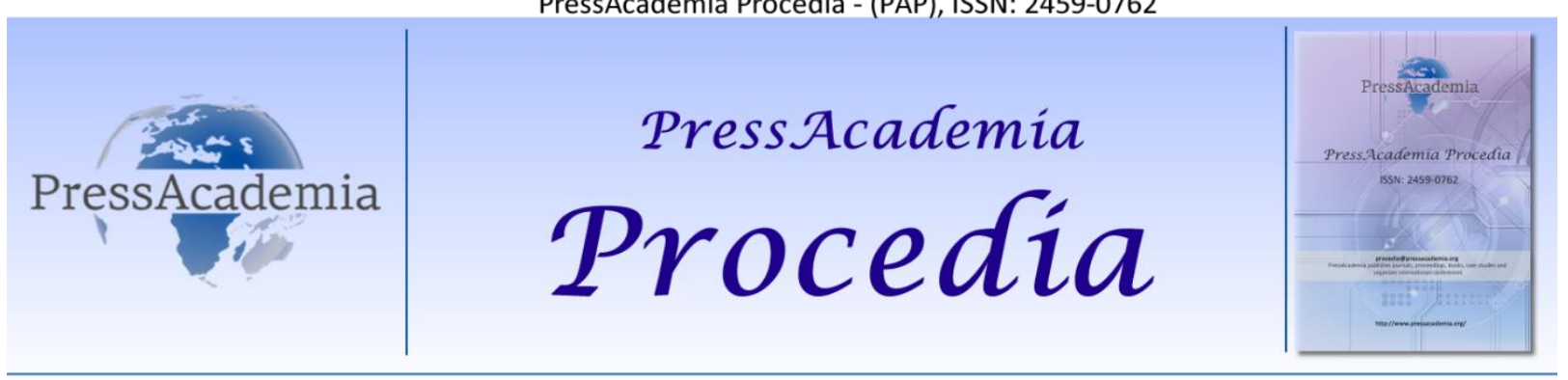

2nd World Conference on Technology, Innovation and Entrepreneurship

May 12- 14, 2017, Istanbul, Turkey. Edited by Sefer Şener

\title{
KNOWLEDGE MANAGEMENT AS A TOOL TO CREATE VALUE: CASE STUDY IN ALGERIAN ENTERPRISES
}

\author{
DOI: 10.17261/Pressacademia.2017.539 \\ PAP-WCTIE-V.4-2017(31)-p.231-244
}

\section{Smahi Ahmed}

University of Tlemcen, Algeria. smahis2002@yahoo.fr

\begin{abstract}
Actually, many enterprises around the world have started taking more attention to their changing environment, mainly with the rise of the big data and information among enterprises as well as their stakeholders, thereby, enterprises are trying to improve their performance and creating more value, via the best exploitation of their available resources. Therefore, this work aims to study the impact of knowledge management in value creation within the Algerian enterprises. In addition, we try to give a whole situation of the KM application in the Algerian enterprises through the practical study. From one hand, the result of this study is very important in the term of the Algerian leader's interest about creation value through knowledge management, but from another hand, they need more efforts to increase their capacities and improving the practice of knowledge management in their enterprises as an official organizational structure.
\end{abstract}

Keywords: Knowledge management, value creation, knowledge value, KAVS, algerian enterprises JEL Codes: D83, N75, 125

\section{INTRODUCTION}

Companies today are living in a very changing environment. They conduct their activities in accordance with predetermined and very defined local and international conditions. These conditions impose on managers to properly mastering the mechanisms and necessary strategies to survive and to face different increasing competitive challenges. Economy, culture, society, natural space, technology and the state of competition influence to a large extent, they do not determine absolutely, business behavior it being understood that each of these particular variables intervene in a manner and pace that is peculiar to it. Nevertheless, the company assimilates, fits reacts. Like any living organism, it accepts or rejects more or less external constraints. Its strength lies in its strategic and ability to transform these constraints into opportunities to change the impasses prosperity deposits, malfunctions into effective action. Creative ideas, innovations, new production methods, diversification of structures, new organizations, the specifics knowledge of the organization and markets, the use of technology, are powerful strategic levers that allow adaptation and differentiation, change and organized the successful action. In this environment characterized by complexity, the information technology (IT) are becoming very dominant, and represent a strong platform and a very useful tool for capturing and collecting permanent information, and allowing to transformer these information to new knowledge, to improve the enterprise performance and realize sustainable competitive advantage. There are many other tools and methods that allow to the managers to create and disseminate new knowledge within the organization such as SECI model of Nonaka and Takeuchi, Feedback Experience, Knowledge Management Discovery Process ... ect.

A successful strategy for implementing a knowledge management system need to combine harmonically between the different aspects on two levels, first an operational level, methods, tools and tactics and second on the strategic level, they need to integrate human capital, knowledge process management, the organizational factors and the contribution of IT to achieve the main objectives. Knowledge considered as intangible or immaterial asset, it is now the main source of productivity and business competitiveness. It is presented in two categories within organization: Explicit knowledge and tacit knowledge. "...According to Nonaka and Takeuchi (1995), explicit knowledge is formal and systematic and it can be expressed in words and numbers. Moreover, it can easily be processed by computers ... Tacit knowledge in turn, is very 
personal and difficult to make visible because of its abstract character. Tacit knowledge includes subjective views, intuition and perceptions as well as experience, ideas, values and feelings... ${ }^{1}$

\section{Introducing Knowledge Management}

In the twenty-first century, the knowledge management consider as the crucial and decisive factors that determined the competitive position of the enterprise in the market (Richards, 2002). It can also be widely regarded as one of the most valuable and efficient capitals in the enterprises and it can be a powerful foundation for developing of large number organizational strategies. The organizational approaches have been altered from emphasizing tangible resource to focusing on intangible resources. As an intangible asset, knowledge is a vital indicator for organizational success that needs to be managed skillfully (Allameh et al., 2014).

\subsection{Knowledge Characteristics}

In general, it exists three types of Knowledge characteristics, which are data, information and Knowledge but according to other researchers we can find four characteristics the last three types plus the wisdom. In our study we adopt the four types or witch called often The DIKW Pyramid or The DIKW Hierarchy.

\section{Fig. 1: Model of Ackoff's DIKW hierarchy}

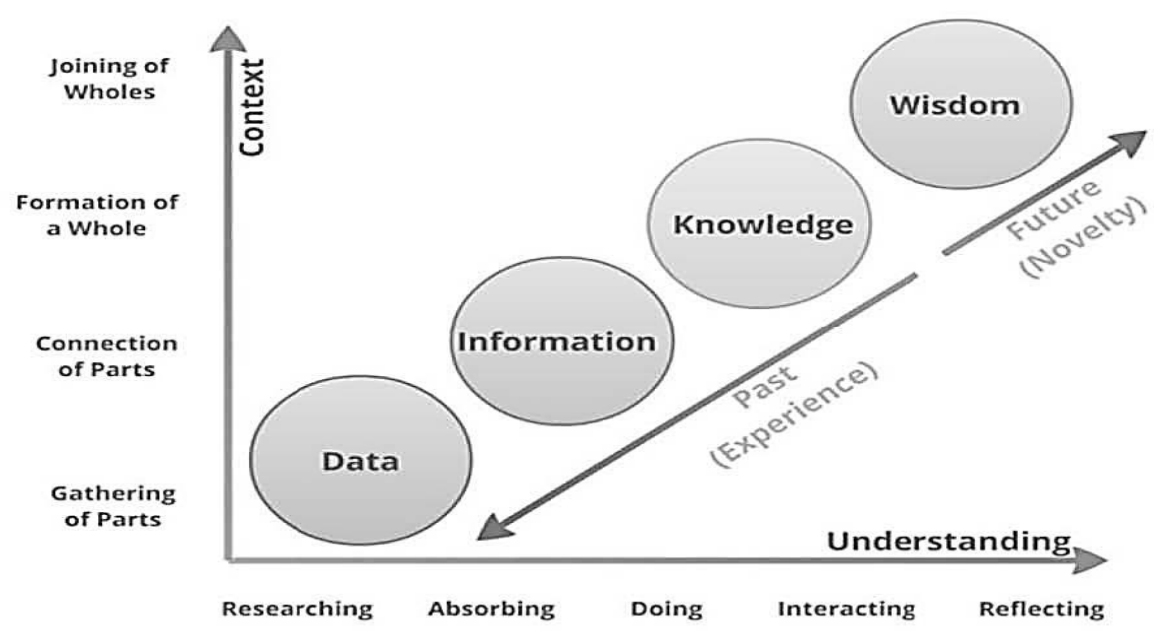

Source: Williams, (2014).

\subsection{Knowledge Categories and Types}

\subsubsection{Knowledge categories}

In his various studies as well as mentioned in his different books concerning the Knowledge Management and Information Technology Management, "Petter Gottschalk" classifies the Knowledge in three principal categories: Core, Advanced and Innovative knowledge.

\section{Core knowledge}

"...This is the type of knowledge that can create efficiency barriers for entry of new companies, as new competitors are not up to speed in basic business processes. Since core knowledge is present at all existing competitors, the firm must have this knowledge even though it will provide the firm with no advantage that distinguishes it from its competitors" ${ }^{2}$.

Core knowledge is that minimum scope and level of knowledge required just staying in business. Having that level of knowledge and capability will not assure the long-term competitive viability of the firm, but does present a basic industry knowledge barrier to entry.

\section{Advanced knowledge}

"...Advanced knowledge enables a firm to be competitively viable. The firm may have generally the same level, scope or quality of knowledge as its competitors although the specific knowledge content will often vary among competitors,

\footnotetext{
${ }^{1}$ Puusa, A. and Eerikäinen, M. “Is Tacit Knowledge Really Tacit?" Electronic Journal of Knowledge Management, Vol. 8, p. 309

${ }^{2}$ Gottschalk, P. (2007). Business dynamics in information technology, ed. IGP. Pp. 114
} 
enabling knowledge differentiation. Firms may choose to compete on knowledge head-on in the same strategic position, hoping to know more than a competitor." ${ }^{3}$

What makes the firm competitively visible and active?, such knowledge allows the firm to differentiate its products and services from that of a competitor through the application of superior knowledge in certain areas. Such knowledge allows the firm to compete head on with its competitors in the same market and for the same set of customers.

\section{Innovative knowledge}

"Innovative knowledge is that knowledge that enables a firm to lead its industry and competitors and to significantly differentiate itself from its competitors" 2 .

Allows a firm to lead its entire industry to an extent that clearly differentiates it from competition. Such knowledge allows a firm to change the rules of the game by introducing new business practices. Such knowledge enables a firm to expand its market share by winning new customers and by increasing service levels to existing customers.

\subsubsection{Knowledge Types}

\section{Explicit Knowledge}

Typically, the explicit knowledge refers to knowledge that has been expressed into words and numbers. Such knowledge can be shared formally and systematically in the form of data, specifications, manuals, drawings, audio and videotapes, computer programs, patents, and the like. It should also be noted that although explicit knowledge might resemble data or information in form.

Also the rules about how to process a travel reimbursement, which becomes embedded in an enterprise resource planning system, is considered explicit knowledge.

\section{Tacit Knowledge}

In contrast, tacit knowledge includes insights, intuitions, and hunches. It is difficult to express and formalize, and therefore difficult to share. Tacit knowledge is more likely to be personal and based on individual experiences and activities.

Tacit knowledge may also include expertise that is so specific that it may be too expensive to make explicit; therefore, the organization chooses to let it reside with the expert. ${ }^{4}$

\subsection{Knowledge Management}

The twenty-first century, the knowledge management consider as the crucial and decisive factors that determined the competitive position of the enterprise in the market (Richards, 2002). It can also be widely regarded as one of the most valuable and efficient capitals in the enterprises and it can be a powerful foundation for developing of large number organizational strategies.

The organizational approaches have been altered from emphasizing tangible resource to focusing on intangible resources. As an intangible asset, knowledge is a vital indicator for organizational success that needs to be managed skillfully (Allameh et al., 2014).

According to Dalkir, K (2005), and as it illustrated in the following figure, the multidisciplinary nature of Knowledge Management represents a double edged sword. It becomes very important to be able to list and describe what set of attributes are necessary and are in themselves sufficient to constitute knowledge management both as a discipline and as a field of practice.

\footnotetext{
${ }^{3}$ Ibid., p. 3.

${ }^{4}$ For more distinction between Explicit Knowledge and Tacit Knowledge, see Holste and Fields,(2010),
} 
Figure 2: The Interdisciplinary Nature of Knowledge Management

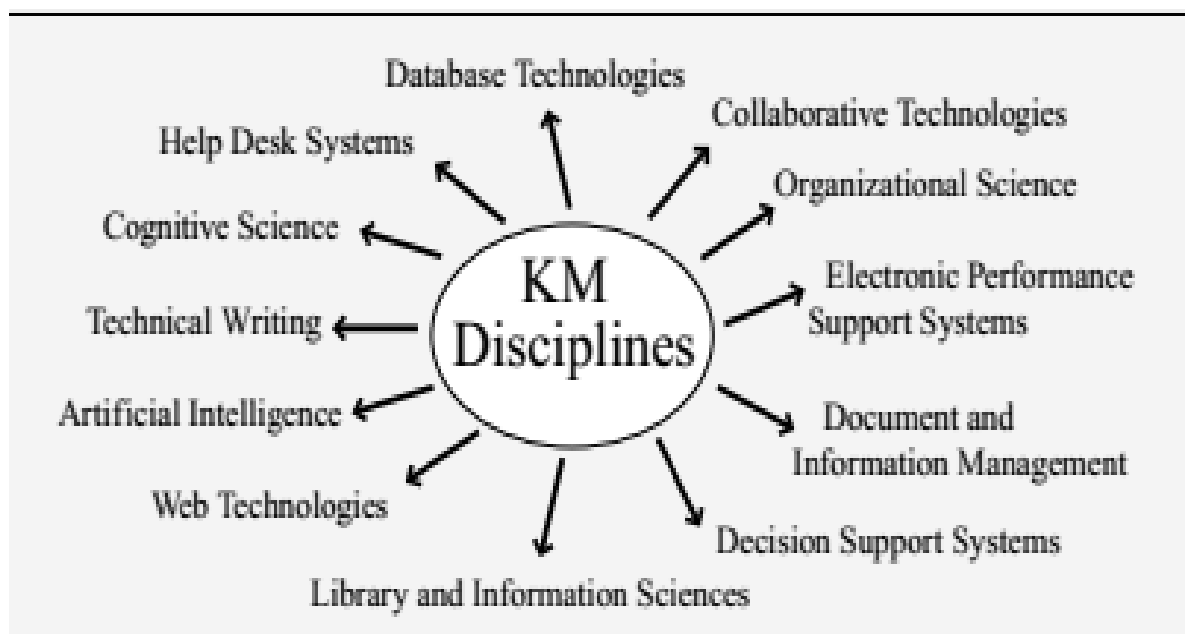

Source: Dalkir. K, 2005

\subsubsection{KM Definition}

There are numerous definitions of knowledge management proffered by researchers. But from another side, we can define it very simply as the conversion of tacit knowledge into explicit knowledge and sharing it within the enterprise Uriarte. F. A (2008), define the Knowledge Management as "... the process through which organizations generate value from their intellectual and knowledge based assets... knowledge management is concerned with the process of identifying, acquiring, distributing and maintaining knowledge that is essential to the organization." KM is defined by Jennex. M E, (2007) as "the practice of selectively applying knowledge from previous experiences of decision making to current and future decisionmaking activities with the express purpose of improving the organization's effectiveness..."

\section{Figure 3: KM Perspectives}

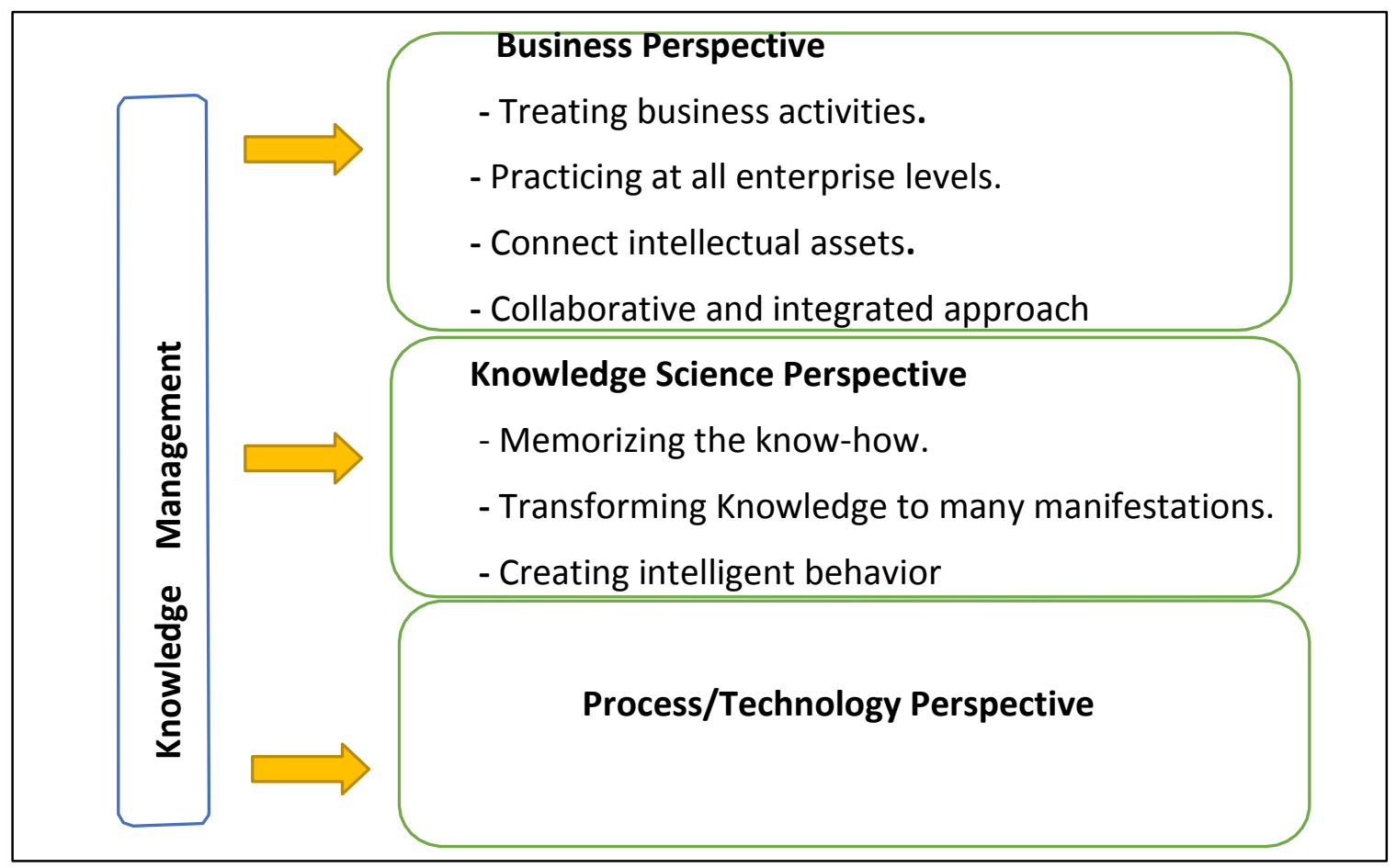

- Information to actionable Knowledge

${ }^{5}$ Jennex. M E, (2007). Knowledge Management in Modern Organizations. Ed IGP. p. 4. 
- Usable knowledge form.

- Sharing between people

\section{From the business perspective}

The definition of KM as a business activity has to take in account two primary aspects:

1 - Treating the knowledge component of business activities as an explicit concern of business reflected in strategy, policy, and practice at all levels of the enterprise.

2 - Making a direct connection between an organization's intellectual assets, that is to say, the both explicit and tacit and the positive business results.

From here, the KM can consider as a collaborative and integrated approach to the creation, capture, organization, access and use of an enterprise's intellectual assets.

\section{From the cognitive science or knowledge science perspective}

Knowledge as like as the insights, understandings, reflection and practical know-how, is the fundamental resource that allows us to function intelligently in the right way.

Over time, the knowledge is also transformed to other manifestations, such as books, technology, practices and traditions within enterprise. These transformations result in cumulated expertise and when used appropriately can increase the enterprise effectiveness.

\section{From the process/technology perspective}

Knowledge management is the concept under which information is turned into actionable knowledge and made available effortlessly in a usable form to the people who can apply it.

\subsubsection{Different definitions of Knowledge Management ${ }^{6}$}

1. Knowledge management is the collection of processes that govern the creation, dissemination, and utilization of knowledge. - Brian Newman

2. Knowledge management is the management of the organization towards the continuous renewal of the organizational knowledge base - this means, for example, the creation of supportive organizational structures, facilitation of organizational members, putting IT-instruments with emphasis on teamwork and diffusion of knowledge (e.g., groupware) into place. - Thomas Bertels

3. Knowledge management is an audit of "intellectual assets" that highlights unique sources, critical functions and potential bottlenecks which hinder knowledge flows to the point of use. - Denham Grey

4. Knowledge management consists of activities focused on the organization gaining knowledge from its own experience and from the experience of others, and on the judicious application of that knowledge to fulfill the mission of the organization. - Gregory Wenig

5. Knowledge management is a business activity with two primary aspects: (a) treating the knowledge component of business activities as an explicit concern of business reflected in strategy, policy, and practice at all levels of the organization; and (b) making a direct connection between an organization's intellectual assets - both explicit (recorded)

and tacit (personal know-how) - and positive business results. - Rebecca O. Barclay and Philip C. Murray

6. Knowledge management is the process through which organizations generate value from their intellectual and knowledge-based assets. - Megan Santosus and Jon Surmacz

7. Knowledge management is the systematic process of finding, selecting, organizing, distilling and presenting information in a way that improves an employee's comprehension in a specific area of interest. - University of Texas

8. Knowledge management is a process with four parts that comprise a loop: knowledge is created, knowledge is captured, knowledge is classified and modified, and knowledge is shared. - Wally Bock

9. Knowledge management is the way that organizations create, capture and re-use knowledge to achieve organizational objectives.- Wally Bock

10. Knowledge management is the way organizations create, capture, enhance, and reuse knowledge to achieve organizational objectives.-Asian Development Bank

11. Knowledge management is a collection of activities, processes and policies, which enable organizations to apply knowledge to improve effectiveness, innovation and quality. - UN Knowledge Management Workshop

\footnotetext{
${ }^{6}$ Uriarte. F. A, (2008). Introduction to Knowledge Management. Ed. ASEAN Foundation. pp. 27-31.
} 
12. Knowledge management is the identification and mapping of intellectual assets within an organization, the creation of knowledge for competitive advantage, the conversion of vast amounts of available corporate data into accessible information and the distribution of best practices. - Economic and Social Commission for Western Asia

13. Knowledge management is the process through which organizations generate value from their intellectual and Knowledge-based assets. - ClO Magazine

14. Knowledge management is concerned with organizing knowledge repositories so as to allow for easy retrieval and exchange of the information stored therein. - Felix Weigel

15. Knowledge management is the process of capturing value, knowledge and understanding of corporate information, using IT systems, in order to maintain, re-use and re-deploy that knowledge.-OIC Document Management

16. Knowledge management is a streamlined approach at improving knowledge sharing across the entire organization. Tenrox PSA

17. Knowledge management is information or data management with the additional practice of capturing the tacit experience of the individual to be shared, used and built upon by the organization. - KMTool Community

18. Knowledge management is organizing information from disparate sources into a context that reflects the business and the decisions and processes of the business. - Peter Novins

19. Knowledge management is the strategy and processes to enable the creation and flow of relevant knowledge throughout the business to create organizational, customer and consumer value. - David Smith

\subsubsection{Knowledge Management Objectives}

There are some typical knowledge management objectives (Dalkir, 2005 \&Uriarte, 2008). These last are summarized in the following points:

1 - Facilitate a smooth transition from those retiring to their successors who are recruited to fill their positions.

2 - Minimize loss of corporate memory due to attrition and retirement.

3 - Identify critical resources and critical areas of knowledge so that the corporation "knows what it knows and does it well-and why."

4 - Build up a toolkit of methods that can be used with individuals, with groups, and with the organization to stem the potential loss of intellectual capital.

5 - Marketplaces are increasingly competitive and the rate of innovation is rising.

6 - Reductions in staffing create a need to replace informal knowledge with formal methods.

7 - Competitive pressures reduce the size of the work force that holds valuable business knowledge.

8 - The amount of time available to experience and acquire knowledge has diminished.

9 - Early retirements and increasing mobility of the work force lead to loss of knowledge.

10 - There is a need to manage increasing complexity as small operating companies are transnational sourcing operations.

11 - Changes in strategic direction may result in the loss of knowledge in a specific area.

\section{KMV Configuration in the Algerian Enterprises}

\subsection{The Case Study Sample Presentation}

\subsubsection{The Characteristics of Selected Sample}

\section{Purpose of the study}

Our aim from the present case study is to define from one side, the real situation of KM application in the Algerian enterprises and from another side, the value created within the enterprise according to the leaders' engagement.

\section{The sample selection and the response rate}

In this study, we have contacted about 62 enterprises spread over various Wilaya, using rinted questionnaires (personal interviews in Tlemcen) and questionnaires online with Google Drive (email and Facebook messages in different regions). But the result is not enough at all, from one hand, we have recovered only $25,80 \%$ of questionnaires equivalent to 16 enterprises whose $12.5 \%$ recovered data are from Google Drive. And from another hand, all the answers by Internet are from Tlemcen which require that all enterprises in this case are from Tlemcen. 


\section{Identification of the enterprise}

In this part, we have to present the size of enterprises, property type and the enterprises' different activities. All data in this chapter will be analyzed using statistical software (Minitab Ver.17).

\section{Size and Property type}

The following figure represents the different size of the enterprises. The sample contents all categories of size: two micro enterprises (12.5\%), five small enterprises (31.3\%), four medium enterprises (25\%) and five big enterprises (31.3\%). The private enterprises represent the majority with $62.5 \%$ equivalent to ten enterprises. In contrast the public enterprises are equal to six enterprises.

\section{Figure 4: Enterprises'size}
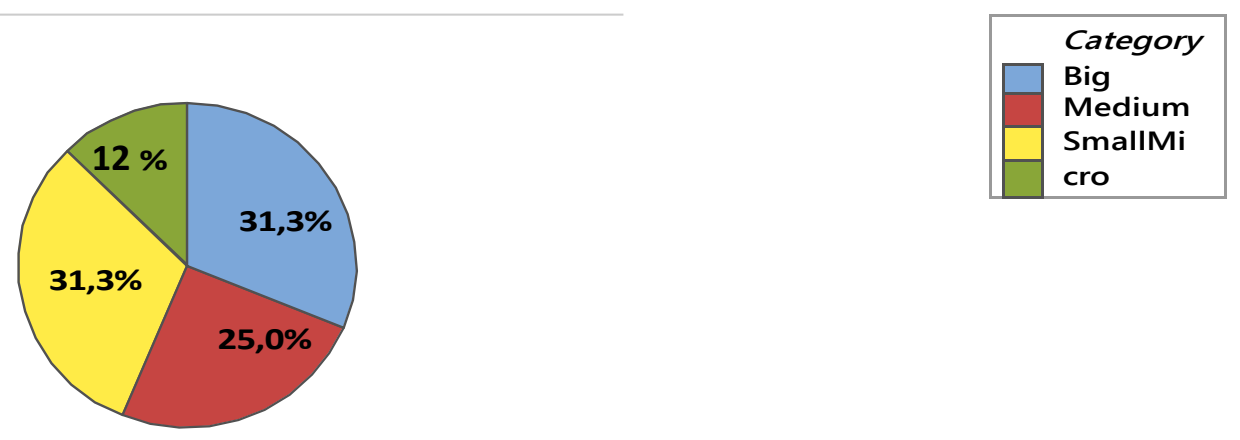

Figure 5: Enterprises Property Type
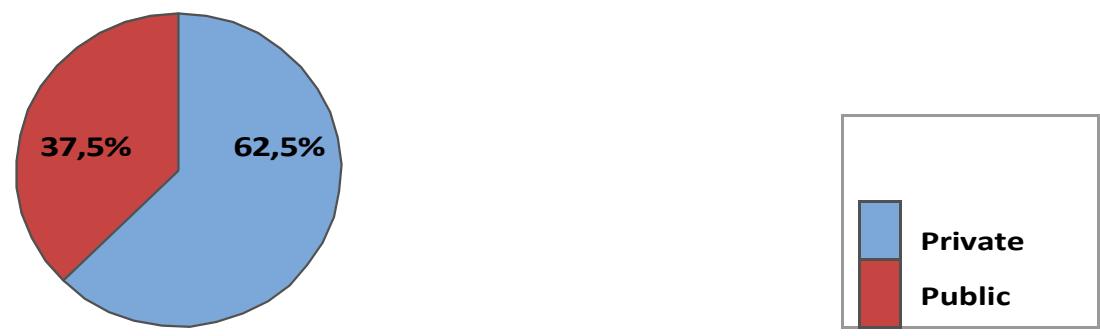

\section{More characteristics (Activities)}

Generally, we can find in the table 1, the name of the enterprises and their principal activities ordered by Size, Property type and creation date. This last as well as figured in the table represent a various age from 1971 until 2013.

Table 1 : Enterprises' characteristics

\begin{tabular}{|c|c|c|c|c|}
\hline Enterprise Name & Creationdate & Size & $\begin{array}{l}\text { Property } \\
\text { Type }\end{array}$ & Main Activity \\
\hline SDO- Direction de Tlemcen & --- & Big & Public & Distribution of electricity and gas \\
\hline STARR & 1971 & Big & Public & Earthworks, Construction, Road Construction \\
\hline SOGERHWIT & 1973 & Big & Public & Public Works, Hydraulic Works \\
\hline SEROR & 1982 & Big & Public & $\begin{array}{l}\text { Public works(bridges, dams and hydropower } \\
\text { facilities, buildings) }\end{array}$ \\
\hline
\end{tabular}




\begin{tabular}{|c|c|c|c|c|}
\hline $\begin{array}{l}\text { AlgérieTélécom-Direction } \\
\text { opérationnelle }\end{array}$ & 2003 & Big & Public & Telecommunications \\
\hline Sarl SOCOPE & 2002 & Medium & Private & Vehicle dealer ship public works \\
\hline EURLBHT Contructions & 2010 & Medium & Private & Public Works, Construction \\
\hline EURL BIAConstruction & 2013 & Medium & Private & Public Works, Construction \\
\hline EMACO, Spa & 1972 & Medium & Public & Production \& Commerc. Building Materials \\
\hline Groupe Gourmala & 1988 & Small & Private & Public Works, Hydraulics \\
\hline SARL S.B.C & 1994 & Small & Private & Agglomerated-tiling \\
\hline SARL SNEF & 2001 & Small & Private & Textiles, manufacturing blankets, Spinning, Weaving \\
\hline SARLTECHAM & 2007 & Small & Private & Modular Construction, Land scaping workspace \\
\hline Zino broderie & 2010 & Small & Private & Industrial embroidery \\
\hline SARL El ouahab & 2005 & Micro & Private & Dry fruits \\
\hline Djellab Moulay Habib & 2006 & Micro & Private & Mechanical construction \\
\hline
\end{tabular}

\subsection{The characteristics of $\mathrm{KM}$ in the Algerian enterprise}

\subsubsection{Knowledge Creation}

From one side, $68.8 \%$ of enterprises have a KM Service or group (Fig. 6), in same time we can observe that only $37.5 \%$ of enterprises have a monitoring unit to collect relevant information and $25 \%$ of them rely on R\&D to increase and create new knowledge. And from another side, all enterprises (100\%) consider the knowledge as organization assets and $87.5 \%$ of them consider these last as a strategic asset (Fig.7).

\section{Figure 6: Having a Knowledge Management Service}

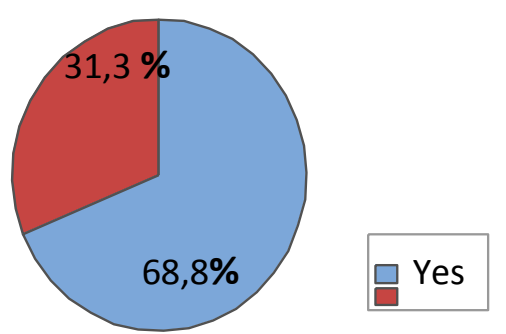

Figure 7: Stacked Enterprises For Knowledge As Assets By Strategic Asset 


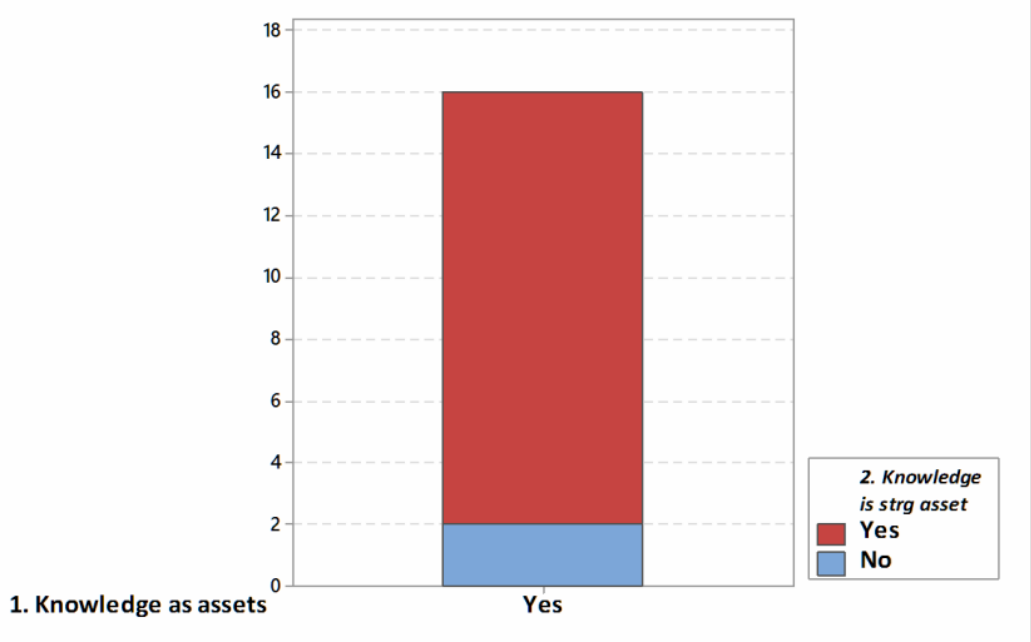

In term of collecting information all enterprises (100\%) are able to collect the necessary information and $87.5 \%$ of them can deal this information according to their needs (Fig.8). But only $43.8 \%$ have KM Process in their own systems (Fig. 9).

Figure 8: Cluster of Enterprises by Collecting Information and Dealing information

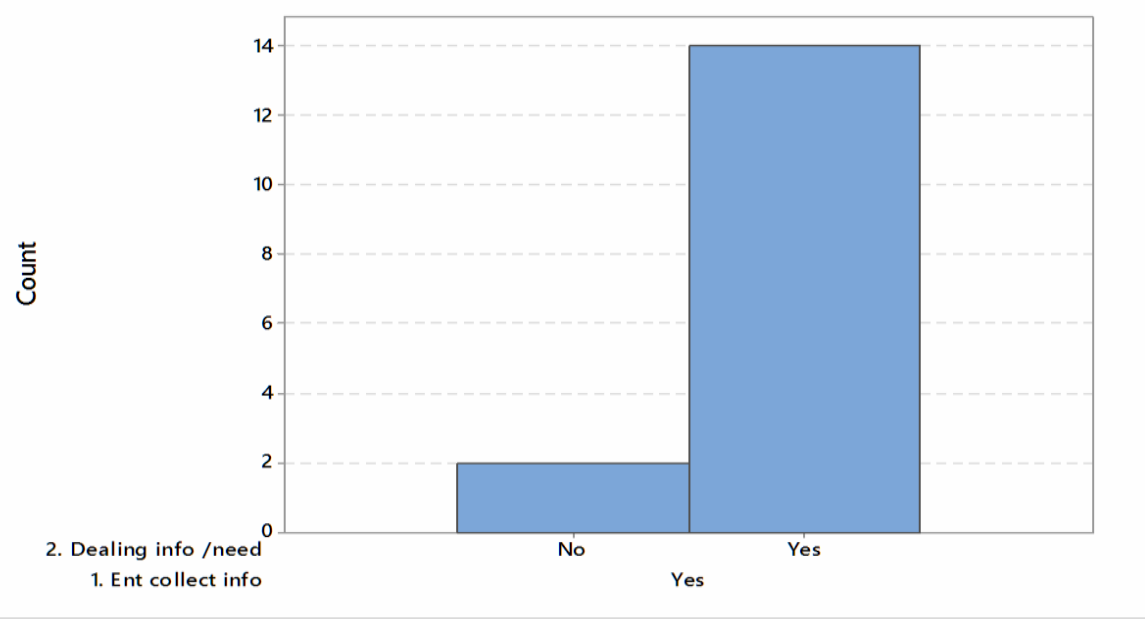

Figure 9: Having KM Process

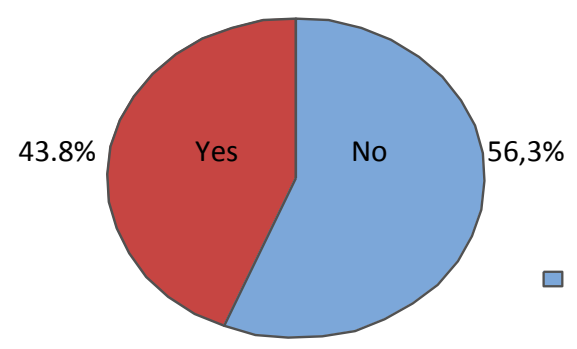

87.5\% of enterprises consider that their employees play an important role in the process of knowledge creation (Figure 10).

Figure 10: Employees Role in Knowledge Creation 


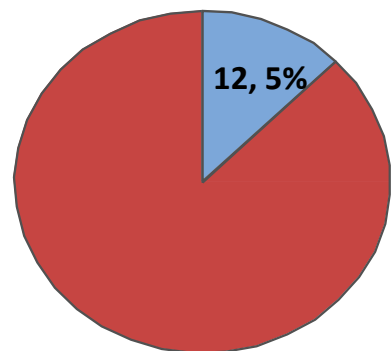

$87,5 \%$

\begin{tabular}{|l|l|}
\hline \multicolumn{2}{|c|}{ Category } \\
\hline No \\
Yes
\end{tabular}

\subsubsection{Knowledge Storage and Sharing}

About $56.3 \%$ of enterprises use paper to store Knowledge. In contrast we can find $75 \%$ use electronic media as a tool for storage. The majority of enterprises $93.8 \%$ considers training and interne learning as a tools to store and transfer knowledge (Figure 11).

\section{Figure 11: Training as a Tool To Store and Transfer Knowledge}
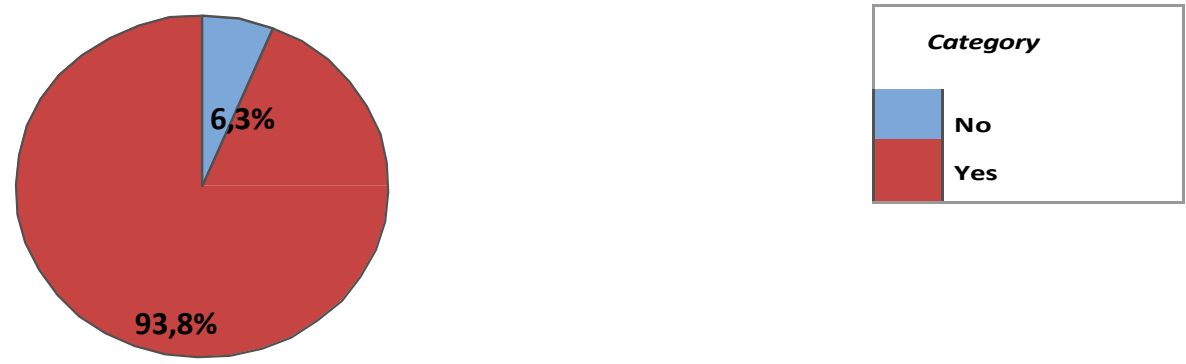

From another hand, only $37.5 \%$ of enterprises use textbooks or manuals to store and share their knowledge. In contrast, there are $68.8 \%$ of enterprises integrate Knowledge in their managerial and manufacturing procedures to share it (Fig.12).

Figure 12: K Integration In Managerial and Manufacturing Procedures

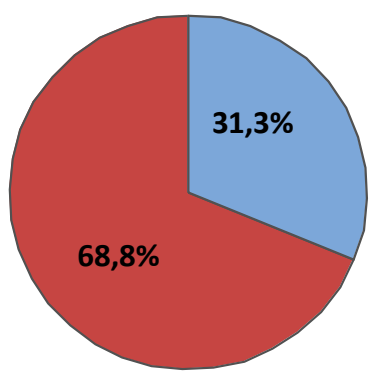

Category

No 
All enterprises are agreeing with $100 \%$ that the work as a team allows to the employees the best sharing and creating a new knowledge. Following to this information, we note that only $75 \%$ of enterprises declare that their knowledge creators are rewarded (Figure 13).

\section{Figure 13: The Knowledge Creators Are Rewarded}
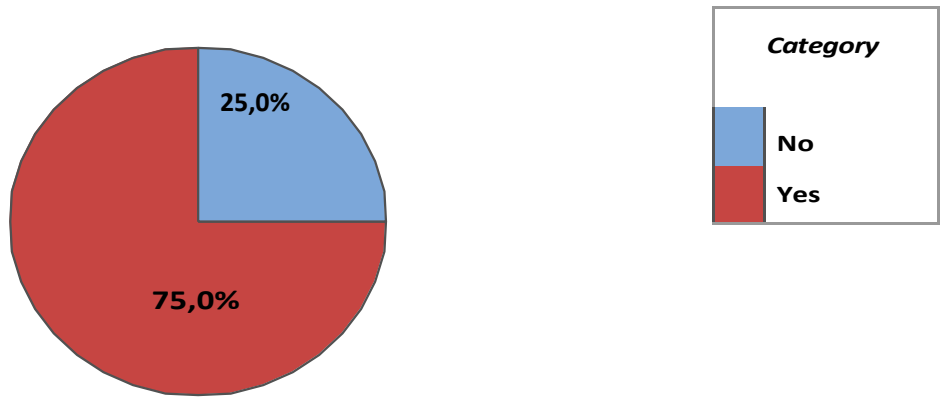

\subsubsection{Knowledge Utilization}

$87.5 \%$ of the cumulative knowledge in Algerian enterprise is very helpful and a best tool to develop and manage the new projects (Figure 14).

\section{Figure 14: Using Cumulative Knowledge to Manage New Projects}

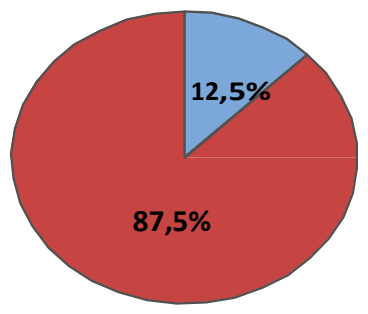

Category

No

Yes

All enterprises (100\%) use the Knowledge to solve their problems and $56.3 \%$ of them allow to their employees the access to the appropriate knowledge. $68.8 \%$ of this knowledge is considered as a strategic resource. For more efficient, $81.3 \%$ of enterprises integrate their competent employees into the product development process (Figure 15).

\section{Figure 15: Employees Integration into The Product Development Process}

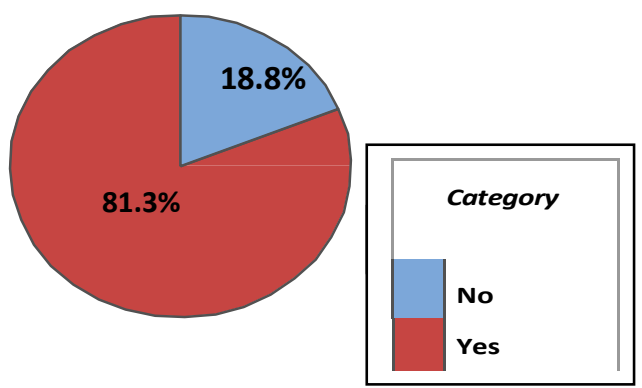

2.2.4. Knowledge Management and ICT 
The ICT play a very important role in developing information within enterprise. In our case, we can observe that $50 \%$ of enterprises use IS and ERP to develop the knowledge. And $68.8 \%$ of them are ready to adopt a new technologies as mobile application to enhance the knowledge creation process (Fig.16).

\section{Figure16: Adopt New Technologies To Develop KM}

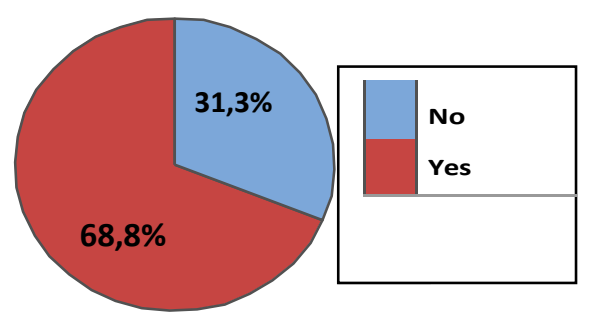

\subsection{KMVC In The Algerian Enterprise}

2.3 1.The impact of KM on Decision Making In the next Figure (Fig. 25), we note that the majority of leaders (93.8\%) rely on knowledge to make decisions

2.3 2. The impact of $K M$ on enterprise profitability

The efficient of knowledge in terms of profit represent $75 \%$ in our study, $62.5 \%$ in increasing the turnover and $87.5 \%$ in creating added value and saving time.

\subsection{The Knowledge Management Value Configuration}

\subsubsection{The Value Chain}

To improve the performance and reducing costs in the Algerian enterprises through KM represent $93.8 \%$ in this case. In Addition, $87.5 \%$ of them use KM to increase their productivity and $68.8 \%$ to increase and improve the creativity. As a result, $62.5 \%$ of enterprises use KM to acquire a competitive advantage.

\begin{tabular}{|l|c|c|}
\hline & yes & no \\
\hline Using KM to improve performance & $93,8 \%$ & $6,3 \%$ \\
\hline Knowledge is profitable in terms of Costs & $93,8 \%$ & $6,3 \%$ \\
\hline Using KM to increase the productivity & $87,5 \%$ & $6,3 \%$ \\
\hline
\end{tabular}

\subsubsection{The Value Shop}

Solving customer's problems is one of the priorities in the enterprise. Using KM to satisfy and retain the customers represent $81.3 \%$, in this study and $87.5 \%$ to enhance the quality.

\begin{tabular}{|l|l|l|}
\hline & yes & no \\
\hline KM using to satisfy and retain the customers & $81,3 \%$ & $18,8 \%$ \\
\hline Knowledge is profitable in terms of Quality & $87,5 \%$ & $12,5 \%$ \\
\hline
\end{tabular}

\subsubsection{The Value Network}

The information collected by putting the partners or more practically the customers in connection each to other, visualized in the next table, $62.5 \%$ of leaders share their Non-strategic knowledge with their partners. The same rate (62.5\%) we can note in the use of Internet as tool to communicate with different partners. One of the recent web technics using to analysis data and creating customers' knowledge are the social networks. These last are weakly used by the Algerian enterprises, only $37.5 \%$ of enterprises use this technic.

\begin{tabular}{|l|c|c|}
\hline & yes & no \\
\hline Non-strategic Knowledge sharing with partners & $62,5 \%$ & $37,5 \%$ \\
\hline Using internet in communication with partners. & $62,5 \%$ & $37,5 \%$ \\
\hline Using social networks to collect information & $37,5 \%$ & $62,5 \%$ \\
\hline
\end{tabular}

The previous statistics reflect, from one side, the importance of creating value in the enterprise 
and from another side the negligence in some case of knowledge activities.

Table 2: The Contribution of KM to Create Value in Algerian Enterprises

\begin{tabular}{|c|c|c|}
\hline The Value Chain & The Value Shop & The Value Network \\
\hline Improving performance & Solving problems & Sharing non-strategic \\
$93.8 \%$ & $100 \%$ & Knowledge \\
Reducing costs & Enhance the quality & $62.5 \%$ \\
$93.8 \%$ & $87.5 \%$ & Communicate by Internet \\
Increase productivity & Sharing non-strategic & $62.5 \%$ \\
$87.5 \%$ & Knowledge & Using social networks \\
Increase creativity & $62.5 \%$ & $37.5 \%$ \\
$68.8 \%$ & Satisfy and retain the & Adopting new technologies \\
Competitive advantage & customers & $68.8 \%$ \\
$62.5 \%$ & $81.3 \%$ & \\
\hline
\end{tabular}

\section{CONCLUSION}

The Knowledge Management as a discipline was and stills the debate of large number of researches around the world. As seen in this work and mainly in the last section, the Algerian Enterprises take in consideration the importance of investment in the KM as intellectual capital. However, the reality of KM practice within Algerian Enterprises as well as we conclude in this study, content two situations. In the first, we note that less than $40 \%$ of enterprises do not have a real knowledge Management services or department to develop and manage the organization knowledge. The R\&D is not deeming as important element to develop and create a new knowledge, it represents only $25 \%$ of leader's importance. In the second situation, the practice of KM as some separated activities, is one of the majority characteristics in the Algerian enterprises. All (100\%) of enterprises are able to collect and treat information. In contrast, only $43.8 \%$ have a knowledge management process. The training and interne learning represent $93.8 \%$ of importance as a tools to store and transfer the knowledge. The employees play an important role in knowledge creation (87.5\%). From another side, we have a weak integration of ICT in knowledge management process. The Knowledge Value Configuration in our case, it was explained through the Algerian leader's interest in the majority of the enterprises. The next table summarizes the obtained results in term of The Contribution of KM to create value according to the model of Gottschalk (2007).

In general, these results are positive, in the terms of the Algerian leader's interest about creation value through knowledge management, but to get a significant relation between the integration of the knowledge management in the Algerian enterprises and the value creation, they need more collaboration with their partners and more efforts to increase their capacities and improving the practice of knowledge management from one side and from another they should clearly define their Knowledge Management process as official process and an integrated part of their organizational structure, not only as separate and secondary activities.

\section{REFERENCES}

Becerra-Fernandez, I. \& Sabherwal, R. (2015). Knowledge Management: Systems and Processes. Ed. Routledge.

Bergeron, B. (2003). Essentials of Knowledge Management. Ed. Wiley. Dalkir, K. (2005). Knowledge Management in theory practice. Ed. Elsevier.

Gottschalk, P. (2007). Business dynamics in information technology. Ed.IGP.

Gottschalk, P. (2007). Knowledge management systems: value shop creation. Ed. IGP.

Hou, H. T. (2012). New Research on Knowledge Management Models and Methods. Ed. InTech.

Ichijo, K. \& Nonaka, I. (2007). Knowledge Creation and Management: New Challenges for Managers. Ed. Oxford university press.

Jennex, M. (2005). Case studies in knowledge management. Ed. IGP.

Jennex, M. (2007). Knowledge Management in Modern Organizations. Ed. IGP.

Lesca, H. \& Lesca, N. (2014). Strategic Decisions and Weak Signals: Anticipation for Decision-Making. Ed. ISTE \& Wiley.

Lesca, H. \& Lesca, N. (2011). Weak signals for strategic intelligence: anticipation tool for managers. Ed. ISTE \& Wiley

Matta, N. et al. (2016). Daily Knowledge Valuation in Organizations: racevability and Capitalization. Ed. ISTE \& Wiley.

Meier, O. (2009). DICO du manager: 500 clef pour comprendre et agir. Ed. Dunod.

Nonaka, I. \& Teece, D. (2001). Managing Industrial Knowledge: Creation, Transfer and Utilization. Ed. SAGE Publications. 
Allameh, S. et al., (2014). Developing a model for examining the effect of tacit and explicit knowledge sharing on organizational performance based on EFQM approach. Journal of Science \& Technology Policy Management, Emerald, Vol. 5 No. 3, pp. 265-280

Bayyurt, N. et al. (2013). System dynamics modeling of a knowledge management process: A case study in Turkish Airlines. 9th International Strategic Management Conference. Ed. Elsevier, p. 546.

Benabderrahmane, Y. (2012). Knowledge Management, ICT deployment and MHR organizations: the case of Algeria, doctoral thesis in management science, University of Paul Valery-Montpellier III, published in HAL review, pp. 228.

Carlucci, D. \& Schiuma, G. (2006). Knowledge Asset Value Spiral: Linking Knowledge Assets to Company's Performance. knowledge and Process Management, Vol 13,Wiley, p. 38

Datoussaid, A. (2015). Corporate strategy and revenue growth in a high intensity

knowledge regime: The case of small and medium Algerian companies, doctoral thesis in management science, University of Tlemcen, pp. 255 .

Ermine. J-L, et al. (2012). Une chaîne de valeur de la connaissance. Management international, HEC Montréal, Vol. 16, pp. 29-40.

Esper, T. et al. (2010). Demand and supply integration: a conceptual framework of value creation through knowledge management. Journal of Academy of Marketing Science, Spring, p. 08

Holste, J. \& Fields, D. (2010). Trust and tacit knowledge sharing and use. Journal of Knowledge Management. Emerald, Vol. 14 Iss: 1 , pp.128 $-140$

Lachachi, A. (2014). La contribution des savoirs dans la performance 'entreprise. Doctoral thesis in management science, University of Tlemcen.

Lachachi, A. (2011). The formalization of knowledge management in the managerial approach: cases of territorial management of Telecom Algeria Tlemcen, Magister thesis in HRM, University of Tlemcen, pp. 228.

Lee, M-C. \& Han, M-W. (2009). Knowledge Value chain model Implemented for Supply Chain Management Performance. International Joint Conference on INC, IMS and IDC, IEEE computer society, the 5th edition, pp 606-611

MALLET, C. (2006). Knowledge Management, ICT and organizational value creation: A proposal for an evaluation model, international conferency of Strategic Management, International Conference of Strategic Management, Geneva, 15th edition, pp. 25

Puusa, A. \& Eerikäinen, M. Is Tacit Knowledge Really Tacit? Electronic

Journal of Knowledge Management, Vol. 8 pp. 309

-Richards, D. (2002). Knowledge in Action: Blurring the Distinction between Tacit and Explicit knowledge. Journal of Decision Systems. Volume 11 - No. 2, pp. 149 - 164. 